\title{
Recurrences of giant cell tumor of bone within soft tissue
}

\author{
Dylan Homen MD, George Brindley MD, Cody Beaver MD
}

\begin{abstract}
Giant cell tumor of bone (GCTB) is typically considered an aggressive but benign tumor, and recurrence of the tumor following surgical intervention is common. It is much rarer, however, for recurrence to occur in the soft tissue surrounding the original lesion. Literature investigating recurrent giant cell tumor of soft tissue is much more limited than literature on bony recurrence, and our understanding of its etiology is still developing. This report reviews two cases in which recurrence of the tumor occurred in the adjacent soft tissue following intralesional excision of GCTB; our aim is to identify variables that could have contributed to this atypical recurrence and to stimulate more investigations into methods for possible prevention.
\end{abstract}

Keywords: giant cell tumor, bone, soft tissue, recurrence

\section{INTRODUCTION}

Giant cell tumor of the bone (GCTB) is a generally benign tumor of fibrohistiocytic origin; it has infrequent pulmonary metastases in 1-2 percent of cases. It is most commonly found in the epiphyseal and metaphyseal region of long bones, especially those in the lower limbs. ${ }^{1}$ This tumor peaks in incidence in patients 20-50 years of age and is problematic due to its tendency to invade surrounding tissue and its high rates of recurrence following excision. While calculated percentages of recurrence vary from study to study (ranging from 12-50 percent), it is generally agreed that the quoted recurrence rates are unacceptable..$^{1,2}$

Very few reported cases have been published regarding recurrences of GCTB within surrounding soft tissues. ${ }^{3}$ This report will review two patients at a single center who presented with a painless mass during follow-up visits for removal of GCT of bone. Each mass was palpable upon physical examination

Corresponding author: Dylan Homen

Contact Information: Dylan.homen@ttuhsc.edu DOI: 10.12746/swrccc.v8i34.661 and confirmed to be recurrent by pathology. The surgical management of each of the original tumors was similar, and we emphasize the surgical procedure to illuminate factors or variables that could have been involved in the recurrence in soft tissue.

\section{CASE 1}

A 21-year-old woman presented at our institution with a mass on the dorsum of her left wrist, adjacent to the incision site from the removal of a giant cell tumor of bone from her left distal radius approximately 22 months prior. The tumor had been removed with curettage and irrigation with normal saline solution, followed by phenolization, cementation with methyl methacrylate, and internal fixation. Upon physical examination of the new mass, a non-tender, mobile soft tissue growth 2-3 centimeters in diameter was noted. It did not transilluminate or appear fluctuant, and plain radiographs were unchanged. Subsequently, an ultrasound guided biopsy of the mass identified the mass as a recurrent giant cell tumor in the soft tissue. Subsequently, the $3 \times 3 \times 4 \mathrm{~cm}$ tumor was removed from its location superficial to the extensor tendons of the wrist, with no observed communication 


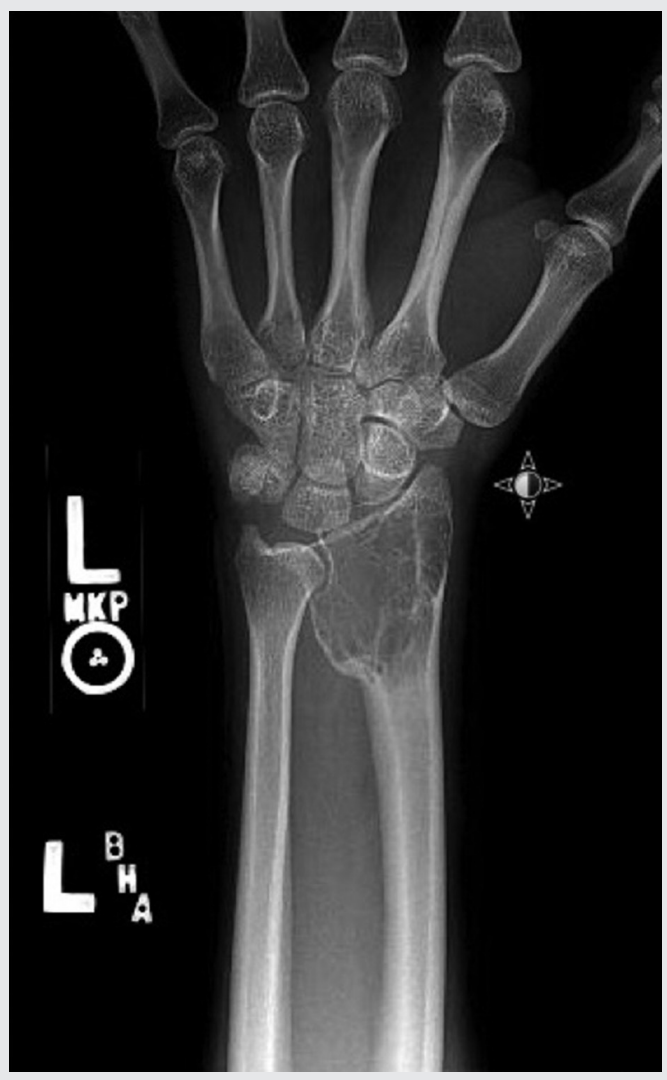

Figure 1A. Preoperative radiograph showing the classically appearing giant cell tumor of the distal radius from the patient in Case 1 .

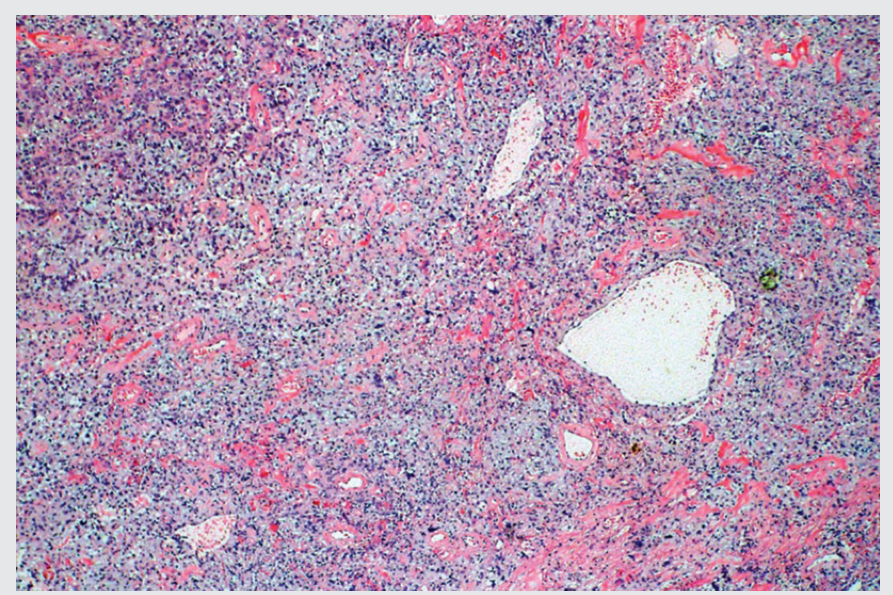

Figure 1B. Histology slide after excision of the bony tumor from Case 1 showing characteristic giant cells.

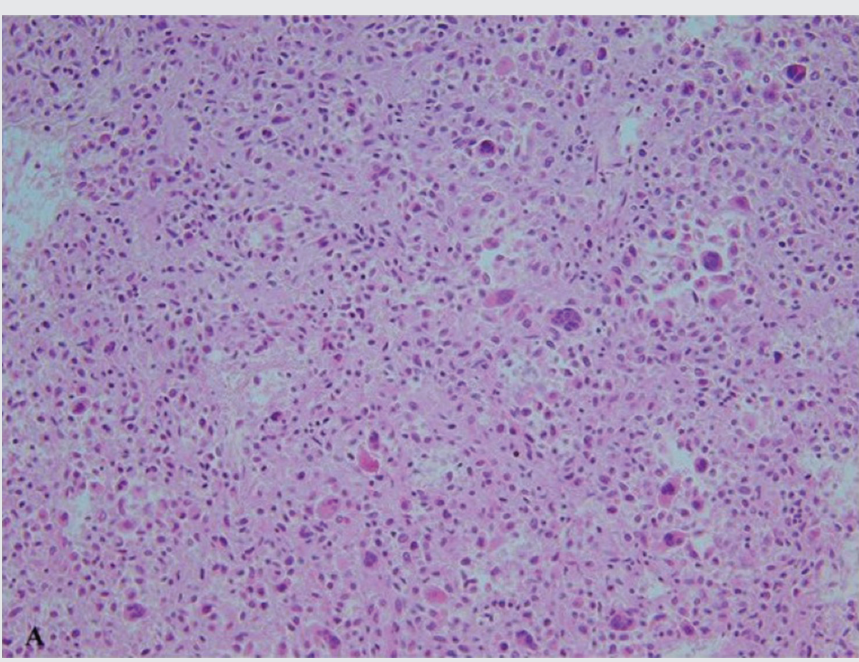

Figure 1C. Histology slide after excision of the recurrent giant cell tumor in soft tissue from patient in Case 1, again showing characteristic giant cells.

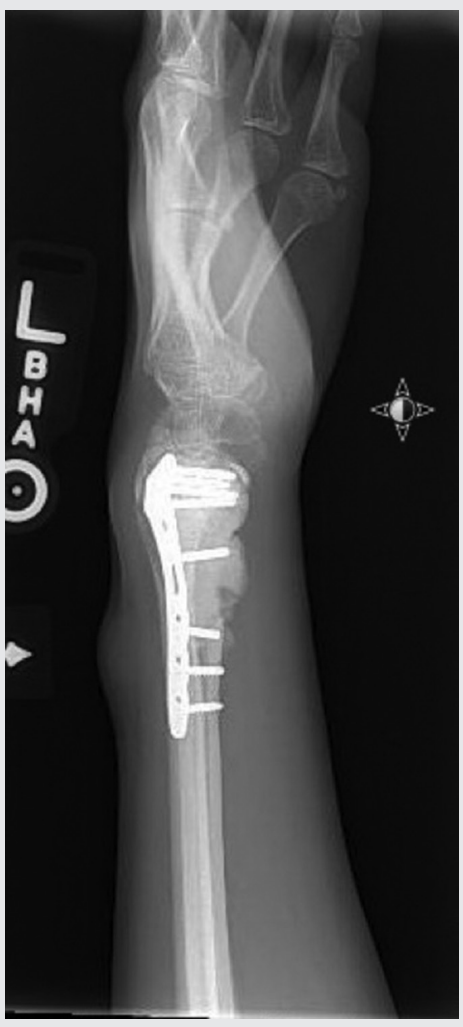

Figure 1D. Preoperative radiograph showing prior hardware and cementation, as well as new soft tissue swelling to the dorsal wrist of patient from Case 1, later confirmed to be recurrent giant cell tumor in the soft tissue. 
with underlying bone. The patient has followed up to this point with no new complaints or evidence of recurrence.

\section{CASE 2}

A 35-year-old man noted a new growth on the anterior aspect of his right proximal leg during a followup visit for previous removal of a giant cell tumor of the proximal tibia, which of note was recurrent. Seven years prior, the patient presented with progressing right knee pain caused by a giant cell tumor of bone on the lateral aspect of the right proximal tibia. The bone tumor was removed via curettage with saline irrigation and was then filled with morselized cancellous chips and methyl methacrylate cement and treated with internal fixation.

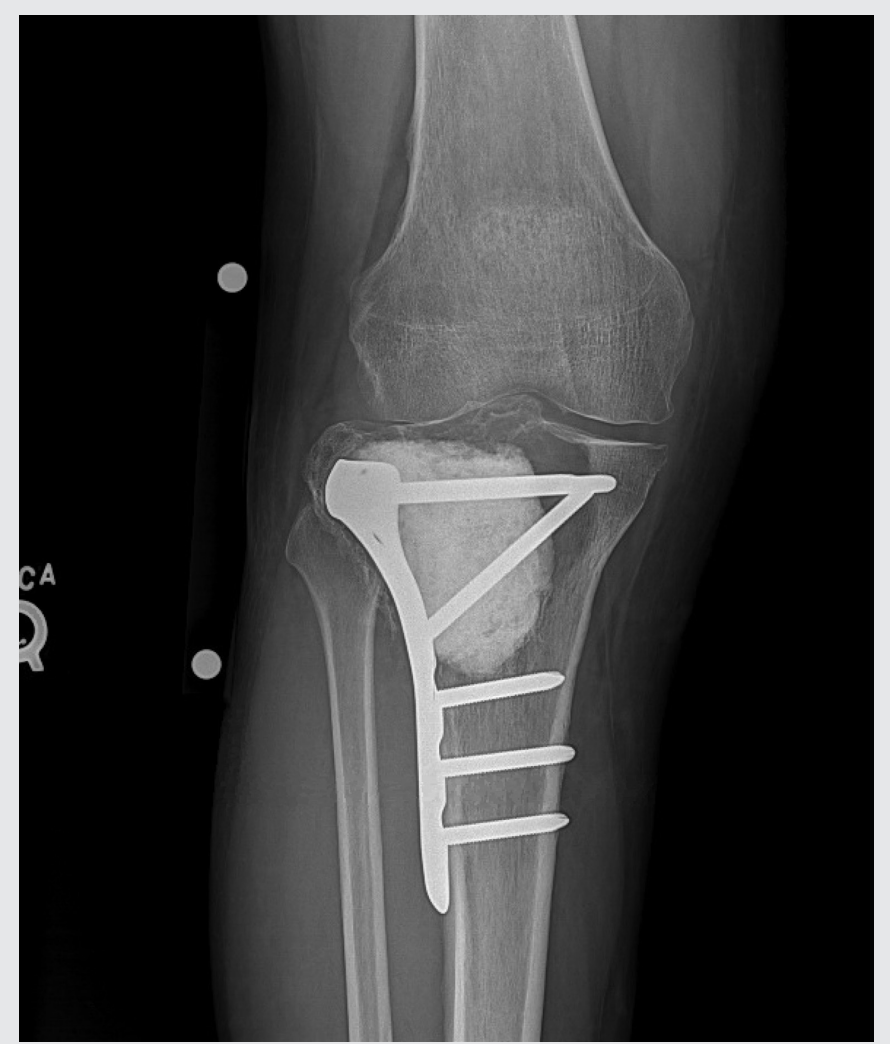

Figure 2A. Preoperative radiographs of the proximal tibia patient from case 2 showing prior hardware and cementation, with new lucency about the cement concerning for recurrent giant cell tumor of bone.
Thirty months after that operation, there was recurrence of the tumor within the bone. This tumor was removed in the same process as the original tumor and refilled with methyl methacrylate cement and once again internally fixated with appropriate hardware. Three years later (approximately 5.5 years after the original diagnosis) the patient had the hardware and cement removed and had the bony defect filled with an autologous bone graft. It was 16 months after this operation that the patient noticed the new growth on his tibia. The mass did not transilluminate, but it was mobile and did not appear fixed to underlying tissue. It was non-tender and mildly compressible. Needle biopsy would confirm that this new mass was a giant cell tumor of soft tissue. The tumor was excised via marginal excision and there was no evidence of bony involvement. Tissue samples that were sent to pathology confirmed negative margins. This patient was lost to follow-up, and information about recurrent disease is not available.

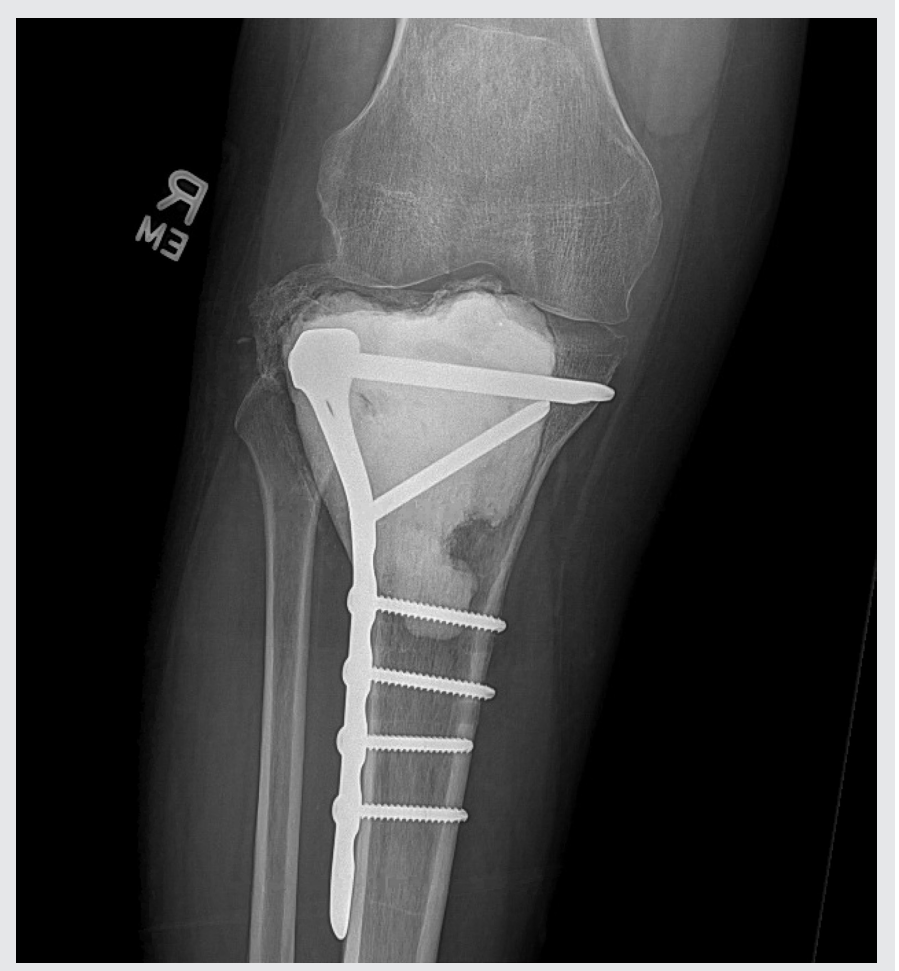

Figure 2B. Postoperative radiographs showing hardware and cement after revision excision of giant cell tumor. 


\section{Discussion}

The rarity of these tumors' recurrences in the soft tissue adds difficulty in identifying risk factors for this type of recurrence. Because the soft tissue tumor is identical to GCT of bone, it has been proposed that risk factors of recurrence in bone may contribute to recurrence in the soft tissue. ${ }^{4}$ The cause of the soft tissue recurrence is believed to be due to implantation of the tumor into the adjacent tissues at the time of surgery. ${ }^{3}$ Thus, meticulous principles of tumor resection (i.e., complete resection of previous biopsy or excision tracts, complete hemostasis) are important to prevent these recurrences. New areas of research in using surgical barrier-type retractors and biopolymers such as Biobarrier (BioActive Polymers, Lund, Sweden) used in abdominal and pelvic tumor resections may provide other means to prevent tumor implantation and seeding. 5,16

Because it can be difficult to excise the tumor with absolutely no contamination, it is postulated that repeated surgical intervention at the tumor site can increase the risk of the soft tissue recurrence. ${ }^{4}$ This is further exacerbated by the fact that recurrence in the bone is common, and thus the surgical site may necessitate multiple operations (as seen in Case 2 of this report). As such, meticulous excision of the primary bony tumor is important to avoid this vicious cycle.

The close proximity of the soft tissue recurrence to the original bone tumor site has also led to hypotheses regarding its etiology. For example, invasion of the bone tumor into the soft tissue was found to be a significant risk factor for tumor recurrence in a study conducted by van der Heijden et al. ${ }^{5}$ While no soft tissue extension was noted in the cases reported here, it is worth noting as a consideration for reducing recurrence in future cases. In addition, Lee et al reported occurrence of GCT-ST in surgical scars of two separate cases. Their report suggested the possibility of linking the development of the tumors to the processes of reparative tissues. ${ }^{3}$

Wide en bloc resection of tumor greatly reduces incidence of recurrence when compared to intralesional curettage..$^{3,5,6}$ Still, curettage remains a preferred method of treatment in many cases, such as the two reported here, as the tumor often extends into the epiphysis and thus adjacent to joint surfaces and wide resection would have unacceptable morbidity.

Multiple studies in the past have demonstrated use of intra-operative adjuvants to reduce risk of recurrence. Commonly used adjuvants include phenol (as used in the above cases), PMMA, argon beam coagulation, anhydrous alcohol, liquid nitrogen, and hydrogen peroxide following curettage has been shown to reduce this risk of recurrence. ${ }^{6}$ However, there are risks associated with their use ranging from tissue necrosis, wound healing and infection complications, nerve or vessel injury from nonspecific tissue damage, and systemic complications of hepatotoxicity and pulmonary fibrosis related to the commonly used adjunct phenol. ${ }^{7-12} \mathrm{~A}$ recent meta-analysis of GCT treatment studies showed that curettage with use of these adjuvant therapies did not show significant decrease in recurrence compared to curettage with high-speed burr alone. ${ }^{13}$ Local adjuvants were used in the index bony tumor excision procedures but due to concern for soft tissue toxicity, they were not used in the soft tissue tumor excisions in the cases described here.

Adjuvant radiotherapy has been used in the past; however, there is a risk of malignant transformation of GCT which is fatal in most cases. ${ }^{15}$ More recently, the recombinant chemotherapeutic drug denosumab has been used to effectively treat GCT of bone. However, more evaluation of the efficacy of this drug on the soft tissue variant of the tumor and its use as adjuvant treatment is needed. ${ }^{14}$

In conclusion, recurrence of giant cell tumor of bone into the surrounding tissue is rare. While the tumor's recurrence in bone has been more frequently investigated, literature regarding recurrence in soft tissue is sparse, and thus support for specific management recommendations is limited. To prevent recurrence in general, strict adherence to standard principles of tumor excision at the index procedure remains vital. Intra-operative adjuvant therapies at the time of the bony tumor excision may help reduce recurrence, but their benefits must be balanced with potential adverse effects and their use in soft tissue recurrence cases needs further exploration. More 
investigation into use of local barriers and systemic medications such as Denosumab is warranted. We hope that this report contributes to our understanding of this rare entity and increases interest in future studies so that we may successfully manage this disease and reduce recurrence rates.

Article citation: Homen D, Brindley G, Beaver C. Recurrences of giant cell tumor of bone within soft tissue. The Southwest Respiratory and Critical Care Chronicles 2020;8(34):56-60

From: Department of Orthopedics, Texas Tech University Health Sciences Center, Lubbock, Texas

Submitted: $2 / 23 / 2020$

Accepted: 4/15/2020

Reviewer: Chok Limsuwat MD

Conflicts of interest: none

This work is licensed under a Creative Commons Attribution-ShareAlike 4.0 International License.

\section{REFERENCES}

1. Van der Heijden L, Van de Sande M, Dijkstra P. Soft tissue extension increases the risk of local recurrence after curettage with adjuvants for giant cell tumor of the long bones. Acta Orthopaedica 2012;83(4):401-405.

2. Rodriguez-Peralto J, Lopez-Barea F, Fernandez-Delgado J. Primary giant cell tumor of soft tissues similar to bone giant cell tumor: a case report and literature review. Pathol International 2001;51:60-63.

3. Lee F, Montgomery M, Hazan E, et al. Recurrent giantcell tumor presenting as a soft-tissue mass. A report of four cases. JBJS Am 1999;81(5):703-707.

4. Siddiqui M, Seng C, Tan M. Risk factors for recurrence of giant cell tumours of bone. J Orthopaedic Surg 2014;22(1): 108-110.
5. van der Heijden L, Dijkstra P, Campanacci D, et al. Giant cell tumor with pathologic fracture: should we currette or resect?. Clin Orthopedics Related Res 2013;471:820-829.

6. Klenke F, Wenger D, Inwards $C$, et al. Recurrent giant cell tumor of long bones: analysis of surgical management. Clin Orthopedics Related Res 2011;469:1181-1187.

7. Lewis V, Wei A, Mendoza T, et al. Argon beam coagulation as an adjuvant for local control of giant cell tumor. Clin Orthopedics Related Res 2007;454:192-197.

8. Becker W, Dohle J, Bernd L, et al. Local recurrence of giant cell tumor of bone after intralesional treatment with and without adjuvant therapy. JBJS Am 2008;90(5):1060-1067.

9. Durr H, Maier M, Jansson V, et al. Phenol as an adjuvant for local control in the treatment of giant cell tumor of the bone. Euro J Surgical Oncology 1999;25(6):610-618.

10. Kivioja A, Blomqvist C, Hietaniemi $K$, et al. Cement is recommended in intralesional surgery of giant cell tumors: a Scandinavian Sarcoma Group Study of 294 patients followed for a mean time of 5 years. Acta Orthopaedica 2008;79(1): 86-93.

11. Quint $U$, Vanhofer $U$, Harstrick A, et al. Cytotoxicity of phenol to musculoskeletal tumours. JBJS Br 1996;78(6):984-985.

12. Radev B, Kase J, Askew M, et al. Potential for thermal damage to articular cartilage by PMMA reconstruction of a bone cavity following tumor excision: a finite element study. J Biomechanics 2009;42(8):1120-1126.

13. Algawahmed H, Turcotte R, Farrokhyar F, et al. High-speed burring with and without the use of surgical adjuvants in the intralesional management of giant cell tumor of bone: a systematic review and meta-analysis. Sarcoma, Article 586090, Vol. 2010.

14. Chakarun C, Forrester D, Gottsegen C, et al. Giant cell tumor of bone: review, mimics, and new developments in treatment. RadioGraphics 2013;33(1):197-211.

15. Canale T,Beatty $\mathrm{W}$, eds. Bone and soft tissue tumors, giant cell tumor. Campbell's Operative Orthopedics, Eleventh ed, 2011: Vol 1, Part VIII, 2181-2183.

16. Posaric-Bauden $M$, Isaksson $K$, Akerberg $D$, et al. Novel anti-adhesive barrier Biobarrier reduces growth of colon cancer cells. J Surg Res 2014;191(1):196-202. 